\title{
BIẾN ĐỔI GIẢI PHẪU MẠCH MÁU THẬN ỬNG DỤNG TRONG GHÉP THậN NGƯờI CHO SỐNG TẠI BỆNH VIỆN VIỆT ĐỨC GIAI ĐOẠN 2012 - 2015
}

\author{
Đoàn Quốc Hung*, Cao Mạnh Thấu*

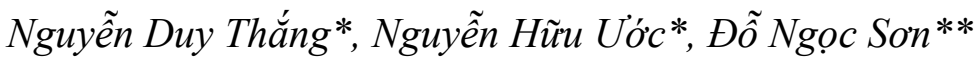

\section{1. ĐẠT VẤN ĐỀ}

Với những thành tựu về miễn dịch học, gây mê hồi sức và ứng dụng công nghệ hiện đại trong điều trị và theo dõi bệnh nhân, ghép tạng nói chung và ghép thận nói riêng đạt được nhiều thành tựu trong những năm gần đây. Tại Việt Nam, ghép thận người cho sống đã trở thành phẫu thuật thường quy tại nhiều trung tâm. Bên cạnh các thăm khám đầy đủ trước ghép, việc nắm vững các biến đổi giải phẫu mạch máu và làm chủ kỹ thuật xử lý mạch máu thận ghép đóng vai trò hết sức quan trọng trong tiên lượng gần và xa của thận ghép[1],[2]. Nghiên cứu này nhằm mục đích mô tả những biến đổi giải phẫu mạch máu thận ứng dụng trong ghép thận người cho sống tại Bệnh viện hữu nghị Việt Đức giai đoạn 2012-2015.

\section{2. ĐỐI TỰ̛̣G VÀ PHƯONG PHÁP NGHIÊN CÚU}

2.1.Đối tượng: Tất cả các trường hợp ghép thận người cho sống được thực hiện tại bệnh viện hữu nghị Việt Đức từ năm 2012 đến tháng 5/2015.

2.2.Phương pháp: Mô tả hồi cứu. Số liệu xử lý bằng phần mềm SPSS 19.0

2.3.Kỹ thuật: Việc tuyển chọn bệnh nhân trước ghép, đánh giá người cho người nhận trước ghép, tất cả quy trình kỹ thuật đánh giá chăm sóc theo dõi trước, trong và sau ghép đều được tuân thủ theo đúng protocol định trước.

Thận lấy trên nguyên tắc đảo bảo an toàn cho người cho thận: thận lấy có xạ hình chức năng thấp hơn hoặc bằng thận để lại. Tất cả các trường hợp đều được chụp cắt lớp 64 dãy có dựng hình mạch máu và siêu âm doppler mạch máu thận. Tất cả biến đổi mạch máu thận được ghi nhận trước ghép, trong quá trình lấy thận và rửa thận. Kỹ thuật khâu nối, đánh giá mạch máu thận đều được thực hiện bởi bác sĩ chuyên khoa mạch máu.

\section{KẾT QUẢ NGHIÊN CÚU}

Trong thời gian nghiên cứu có tổng số 120 cặp ghép thận người cho sống được thực hiện tại bệnh viện hữu nghị Việt Đức. Trong nhóm người cho tỉ lệ nam/nữ 3/1.
Trong nhóm người nhận có 82 trường hợp bệnh nhân nam, 38 trường hợp bệnh nhân nữ (31.67\%).

Tỷ lệ lấy thận bên phải là $54,17 \%$, thận trái là 45.83\%. Đánh giá trước ghép có 51 truò̀ng hơp có biến đổi giải phẫu mạch máu thận, chiếm 42,5\%. Sau lấy thận ghi nhận thêm 7 trường hợp có biến đổi (58 bệnh nhân, chiếm 48.33\%).

Bảng 1. Đặc điểm số lự̣ng mạch máu thận trước ghép $(N=120)$

\begin{tabular}{|c|c|c|}
\hline Đặc điểm mạch máu & Số lượng & Tỷ lệ (\%) \\
\hline 1 ĐM - 1 TM & 87 & 72.5 \\
\hline 1 ĐM - 2 TM & 3 & 2.5 \\
\hline 1 ĐM - 3 TM & 1 & 0.83 \\
\hline 2 ĐM - 1 TM & 25 & 20.84 \\
\hline 2 ĐM - 2 TM & 3 & 2.5 \\
\hline 2ĐM - 3TM & 1 & 0.83 \\
\hline Tống số & 120 & 100 \\
\hline
\end{tabular}

Bảng 2. So sánh biến đổi giải phẫu mạch máu thận trước và sau khi lấy thận

\begin{tabular}{|l|c|c|c|c|}
\hline \multirow{2}{*}{$\begin{array}{c}\text { Đặc điểm biến đổi giải } \\
\text { phẫu }\end{array}$} & \multicolumn{2}{|c|}{$\begin{array}{c}\text { Trước lấy } \\
\text { thận }\end{array}$} & \multicolumn{2}{c|}{$\begin{array}{c}\text { Sau khi lấy } \\
\text { thận }\end{array}$} \\
\cline { 2 - 5 } & $\mathbf{n}$ & $\mathbf{\%}$ & $\mathbf{n}$ & $\mathbf{\%}$ \\
\hline Cuống ĐM thận ngắn & 2 & 1.67 & 2 & 1.67 \\
\hline ĐM thận chia sớm & 4 & 3.33 & 6 & 5 \\
\hline Cuống TM thận ngắn & 3 & 2.5 & 3 & 2.5 \\
\hline ĐM cực nhỏ & 5 & 4.17 & 10 & 8.33 \\
\hline Số lượng ĐM thận chính & 29 & 24.17 & 29 & 24.17 \\
\hline Số lượng TM thận chính & 8 & 6.67 & 8 & 6.67 \\
\hline \multirow{2}{|c|}{ Tổng sốn } & $\mathbf{5 1}$ & $\mathbf{4 2 . 5}$ & $\mathbf{5 8}$ & $\mathbf{4 8 . 3 3}$ \\
\hline
\end{tabular}

* Khoa Phẫu thuật Tim Mạch Bệnh viện Hũu Nghị Việt Đức

** Khoa phẫu thuật tiết niệu Bệnh viện Hũu Nghi Việt Đức Nguoòi chịu trách nhiệm khoa họ: PGS.TS Đoàn Quốc Hung Ngày nhận bài: 10/01/2016 - Ngày Cho Phép Đăng: 24/02/2016

Phản Biện Khoa học: PGS.TS. Đặng Ngọc Hùng GS.TS. Bùi Đức Phú 
Bảng 3. Đặc điểm mạch máu thận rửa

\begin{tabular}{|c|c|c|c|c|c|c|}
\hline \multirow{2}{*}{ Đặc điểm biến đổi giải phẫu } & \multicolumn{2}{|c|}{$\begin{array}{c}\text { Thận phải } \\
(\mathbf{n}=65)\end{array}$} & \multicolumn{2}{|c|}{$\begin{array}{c}\text { Thận trái } \\
(\mathrm{n}=55)\end{array}$} & \multicolumn{2}{|c|}{$\begin{array}{l}\text { Tổng số } \\
(n=120)\end{array}$} \\
\hline & $\mathbf{n}$ & $\%$ & $\mathbf{n}$ & $\%$ & $\mathbf{n}$ & $\%$ \\
\hline Cuống ĐM thận ngắn & 0 & 0 & 2 & 3.64 & 2 & 1.67 \\
\hline ĐM thận chia sớm & 2 & 3.08 & 4 & 7.37 & 6 & 5 \\
\hline Cuống TM thận ngắn & 3 & 4.62 & 0 & 0 & 3 & 2.5 \\
\hline ĐM cực nhỏ & 4 & 6.15 & 6 & 10.91 & 10 & 8.33 \\
\hline Số lượng ĐM thận chính & 20 & 30.77 & 9 & 16.36 & 29 & 24.17 \\
\hline Số lượng tĩnh mạch thận chính & 2 & 3.08 & 6 & 10.91 & 8 & 6.67 \\
\hline Tổng số & 31 & 47.69 & 27 & 49.09 & 58 & 48.33 \\
\hline
\end{tabular}

Bảng 4. Đặc điểm chung mạch máu thận rửa

\begin{tabular}{|l|c|c|}
\hline \multicolumn{1}{|c|}{ Đặc điểm } & Trung bình \pm SD & min- max \\
\hline Chiều dài ĐM thận chính 1 (mm) & $33.41 \pm 8.57$ & $18-50$ \\
\hline Đường kính ĐM thận chính 1 (mm) & $5.38 \pm 1.35$ & $2-9$ \\
\hline Chiều dài ĐM thận chính 2 (mm) & $31.33 \pm 9.71$ & $18-60$ \\
\hline Đường kính ĐM thận chính 2 (mm) & $3.67 \pm 1.43$ & $2-7$ \\
\hline Chiều dài ĐM cực $(\mathrm{mm})$ & $30.38 \pm 6.78$ & $16-49$ \\
\hline Đường kính ĐM cực $(\mathrm{mm})$ & $2.05 \pm 1.01$ & $0.9-4.5$ \\
\hline Chiều dài TM thận chính $(\mathrm{mm})$ & $22.50 \pm 7.98$ & $15-60$ \\
\hline Đường kính TM thận chính $(\mathrm{mm})$ & $10.86 \pm 2.65$ & $4-22$ \\
\hline
\end{tabular}

Bảng 5. Kỹ thuật xử lý bất thường động mạch thận ghép (n=47)

\begin{tabular}{|c|c|c|c|c|}
\hline \multirow{2}{*}{$\begin{array}{l}\text { Đặc điểm biến đổi } \\
\text { giải phẫu }\end{array}$} & \multicolumn{2}{|c|}{ Thận } & \multirow{2}{*}{ Phương pháp xử lý } & \multirow{2}{*}{$\mathbf{n}$} \\
\hline & Phải & Trái & & \\
\hline Cuống ĐM thận ngắn & 0 & 2 & Nối tận bên với ĐM chậu ngoài & 2 \\
\hline \multirow[b]{2}{*}{ ĐM thận chia sớm } & \multirow[b]{2}{*}{2} & \multirow[b]{2}{*}{4} & Carrel Patch ĐMC & 1 \\
\hline & & & $\begin{array}{l}\text { Bảo tồn thân chung } 1 \text { miệng nối tận bên nối với } \\
\text { ĐM chậu ngoài }\end{array}$ & 5 \\
\hline \multirow{3}{*}{ ĐM cực nhỏ } & \multirow{3}{*}{4} & \multirow{3}{*}{6} & ĐM cực - ĐM chậu gốc & 4 \\
\hline & & & Tạo thân chung với ĐM chính & 1 \\
\hline & & & Thắt bỏ & 5 \\
\hline \multirow[b]{2}{*}{2 ĐM thận chính } & \multirow[b]{2}{*}{20} & \multirow[b]{2}{*}{9} & 2 miệng nối ĐM thận - chậu ngoài & 23 \\
\hline & & & $\begin{array}{l}1 \text { miệng nối với ĐM chậu ngoài, } 1 \text { miệng nối với } \\
\text { ĐM chậu gốc }\end{array}$ & 6 \\
\hline Tổng số & 26 & 21 & 47 & \\
\hline
\end{tabular}


Bảng 6. Kỹ thuật xử lý biến đổi giải phẫu tĩnh mạch thận ghép (n=11)

\begin{tabular}{|c|c|c|c|c|}
\hline \multirow{2}{*}{ Đặc điểm biến đổi giải phẫu } & \multicolumn{2}{|c|}{ Thận } & \multirow{2}{*}{ Phương pháp xử lý } & \multirow{2}{*}{$\mathbf{n}$} \\
\hline & Phải & Trái & & \\
\hline \multirow{3}{*}{ Cuống TM thận ngắn } & \multirow{3}{*}{3} & \multirow{3}{*}{0} & $\begin{array}{l}\text { Thắt TM chậu trong } \\
\text { Nối tận bên TM chậu ngoài }\end{array}$ & 1 \\
\hline & & & $\begin{array}{l}\text { Lấy Patch TMC } \\
\text { Nối tân bên với TM châuu ngoài }\end{array}$ & 1 \\
\hline & & & $\begin{array}{l}\text { Cắt đôi TM chậu ngoài } \\
\text { Nối tận tận với TM chậu ngoài } \\
\text { Dùng Homograft tái tạo TM chậu }\end{array}$ & 1 \\
\hline \multirow{3}{*}{02 Tĩnh mạch thận } & \multirow{3}{*}{2} & \multirow{3}{*}{4} & Nối tận bên với TM chậu ngoài & 3 \\
\hline & & & $\begin{array}{l}\text { Thắt TM chậu trong } \\
\text { Nối tận bên với TM chậu ngoài }\end{array}$ & 2 \\
\hline & & & $\begin{array}{l}\text { Thắt TM chậu trong } \\
\text { Ghép đoạn tĩnh mạch sinh dục } \\
02 \text { miệng nối với TM chậu ngoài và chậu gốc }\end{array}$ & 1 \\
\hline \multirow[b]{2}{*}{03 tĩnh mạch thận } & \multirow[b]{2}{*}{2} & \multirow[b]{2}{*}{0} & $\begin{array}{l}\text { Thắt TM chậu trong } \\
03 \text { miệng nối với TM chậu ngoài và chậu gốc }\end{array}$ & 1 \\
\hline & & & $\begin{array}{l}\text { Thắt TM chậu trong } \\
\text { Lấy Patch TMC } \\
\text { Nối } 2 \text { miệng nối với TM chậu ngoài }\end{array}$ & 1 \\
\hline Tổng số & 7 & 4 & 11 & \\
\hline
\end{tabular}

\section{BÀN LUẦN}

\section{1.Đặc điểm biến đổi giải phẫu mạch máu thận người cho sống}

Với siêu âm và chụp cắt lớp vi tính có dựng hình mạch máu đánh giá trước ghép, trong 120 trường hợp chúng tôi ghi nhận có tổng số 51 trường hợp có biến đổi giải phẫu mạch máu thận chiếm $42.5 \%$, trong đó dạng biến đổi số lượng động mạch thận chính (29 trường hợp thận có $2 \mathrm{ĐM}$, chiếm $24.17 \%$ ), bất thường số lượng $\mathrm{TM}$ thận chính có 8 trường hợp, chiếm $6.67 \%$.

Bảng 2 cho thấy, tổng số 58 trường hợp thận rửa có biến đổi giải phẫu mạch máu, chiếm $48.33 \%$. Sau khi lấy thận phát hiện thêm 7 trường hợp có biến đổi giải phẫu, trong đó phát hiện thêm 2 trường hợp động mạch thận chia sớm (tổng số 6 bệnh nhân, chiếm 5\%), và 5 trường hợp động mạch cực nhỏ (tổng số 10 bệnh nhân ,chiếm $8.33 \%$ ). Thận rửa có đặc điểm giải phẫu về mạch máu khác với dự kiến trước mổ có thể do một số nguyên nhân sau: (1) Liên quan đến chẩn đoán trước mổ: những trường hợp ĐM thận chia sớm, hay ĐM cực nhỏ không phát hiện được trên chụp cắt lớp vi tính đa dãy hoặc sai sót trong quá trình đọc phim; (2) Do mặt kỹ thuật lấy thận đặc biệt trong lấy thận phải để ghép, bộc lộ sát nguyên ủy động mạch thận đôi khi gặp khó khăn do vị trí giải phẫu và kinh nghiệm của phẫu thuật viên nên cắt ĐM thận chưa sát nguyên ủy làm ngắn chiều dài thực tế của động mạch thận [6],[7]. Trong nhóm nghiên cứu của chúng tôi, 5 trường hợp nhánh $\mathrm{ĐM}$ cực được phát hiện thêm do kích thước $\mathrm{ĐM}$ cực nhỏ $1 \mathrm{~mm}$, được thắt bỏ trong quá trình lấy thận. 2 trường hợp $\mathrm{ĐM}$ thận chia sớm, trong đó 1 trường hợp phát hiện trong mổ còn 1 trường hợp lấy thận phải không sát nguyên ủy động mạch thận.

\section{2. Đặc điểm kỹ thuật xử lý mạch máu thận} trong ghép thận người cho sống

- Kỹ thuật xư lý ĐM thận: Trong số 29 trường hợp có biến đổi số lượng ĐM thận, có 23 trường hợp thực hiện 02 miệng nối tận bên riêng rẽ với ĐM chậu 
và 6 trường hợp thực hiện 01 miệng nối. Đa phần ĐM thận được nối tận bên với ĐM chậu ngoài với 111 bệnh nhân chiếm $92.5 \%$, có 08 trường hợp ĐM thận nối tận bên với ĐM chậu gốc (trong đó có 2 trường hợp thận có 1 ĐM, 6 trường hợp còn lại thận 2 ĐM: 1 nối với ĐM chậu ngoài, 1 nối với ĐM chậu gốc). Có 1 trường hợp $\mathrm{ĐM}$ thận được nối với $\mathrm{ĐM}$ chậu trong do biến đổi giải phẫu của hệ ĐM chậu người nhận. Tuy nhiên theo tổng kết của Lê Trung Hải và cộng sự [2], nghiên cứu được thực hiện trên 22 cặp ghép thận từ năm 1992 đến tháng 6 năm 2004, tất cả 22 trường hợp $\mathrm{ĐM}$ thận được nối với ĐM chậu trong của người nhận $(100 \%)$.

Trong tổng số 47 trường hợp có biến đổi giải phẫu ĐM thận, có 02 trường hợp cuống ĐM thận ngắn (đều gặp ở thận trái) do kỹ thuật khi lấy thận chưa lấy sát nguyên ủy $\mathrm{ĐM}$ thận. Trong 06 trường hợp ĐM thận chia sớm, có 1 trường hợp được lấy cả vạt ĐMC (Carrel Patch) thực hiện 1 miệng nối tận - bên thông thường với $\mathrm{ĐM}$ chậu ngoài, 5 trường hợp còn lại được bảo tồn thân chung rồi thực hiện 1 miệng nối tận bên với ĐM chậu ngoài. 10 trường hợp thận ghép có ĐM cực nhỏ (5 trường hợp thắt bỏ $\mathrm{ĐM}$ cực kích thước nhỏ, 5 trường hợp bảo tồn $Đ M$ cực trong đó 4 trường hợp nối tận bên $\mathrm{ĐM}$ cực với ĐM chậu gốc, 1 trường hợp tạo hình ĐM cực với ĐM thận chính thành 1 thân động mạch).

Trong một nghiên cứu đánh giá biến chứng liên quan đến miệng nối động mạch thận của Bewick và cộng sự trên 500 trường hợp ghép thận có 384 trường hợp thận có 1 ĐM, 96 trường hợp thận có 2 ĐM, 19 trường hợp thận có 3 động mạch, có 1 trường hợp thận có 4 ĐM [9]. Động mạch thận được nối tận tận với ĐM chậu trong trong 151 trường hợp, tận bên với ĐM chậu ngoài hoặc chậu gốc trong 55 trường hợp, và tận bên với miếng Carrel patch ĐM chủ trong 294 trường hợp. Tác giả nhận thấy rằng, với kỹ thuật Carrel patch ĐM chủ, tỷ lệ huyết khối động mạch thận ghép là thấp nhất tuy nhiên nguy cơ chảy máu cao hơn so với kỹ thuật khác. Đối với thận ghép có 1 ĐM thì việc sử dụng patch động mạch chủ hay không sử dụng patch động mạch chủ cho kết quả tương tự nhau với tỷ lệ chảy máu và huyết khối tại miệng nối của 2 nhóm này đều là $4,7 \%$. Nhưng nếu thận ghép có từ 2 động mạch thận trở lên, việc sử dụng patch động mạch chủ cho kết quả tốt hơn, nhóm có patch động mạch chủ có tỷ lệ chảy máu và huyết khối là $1,8 \%$ trong khi nhóm không có patch là $11,5 \%$ [9].

Liên quan đến kỹ thuật nối động mạch thận với động mạch chậu, Bewick khuyến cáo thực hiện miệng nối động mạch thận ghép tận bên với ĐM chậu ngoài hoặc ĐM chậu gốc. Tác giả cho rằng, kỹ thuật nối ĐM thận tận - tận với ĐM chậu trong có nguy cơ hẹp miệng nối động mạch thận gấp 6 lần so với các kỹ thuật khác [9].

- Kỹ thuật xử lý tĩnh mạch thận: Liên quan giữa số lượng tĩnh mạch thận và số miệng nối tĩnh mạch. Trong 8 trường hợp có biến đổi số lượng tĩnh mạch thận ghép ( 6 trường hợp có 2 tĩnh mạch thận, 2 trường hợp có 3 tĩnh mạch thận). Tất cả 6 trường hợp có 2 tĩnh mạch thận đều được thực hiện miệng nối tận bên với TM chậu. Có 1 trường hợp 3 tĩnh mạch thận, trong đó 2 thân $\mathrm{TM}$ được lấy cả vạt Carrel Patch TMC rồi thực hiện 2 miệng nối với tĩnh mạch chậu, 1 trường hợp 3 tĩnh mạch thận được thực hiện 3 miệng nối với tĩnh mạch chậu. Qua 12 năm tổng kết ghép thận của Lê Trung Hải và cộng sự [2] qua 22 trường hợp ghép thận, chỉ có 1 trường hợp có biến đổi số lượng tĩnh mạch thận dạng (2 tĩnh mạch), 2 tĩnh mạch này được thực hiện miệng nối riêng rẽ (2 miệng nối) với tĩnh mạch chậu ngoài.

Trong 11 trường hợp có 6 trường hợp được thắt $\mathrm{TM}$ chậu trong để di dộng tốt TM chậu ngoài, 2 trường hợp lấy patch $\mathrm{TMC}$ : 01 trường hợp do cuống $\mathrm{TM}$ thận ngắn, 01 trường hợp biến đổi giải phẫu có 3 tĩnh mạch (chủ động lấy phần TMC có 2 tĩnh mạch thận) và thực hiện 02 miệng nối với tĩnh mạch chậu ngoài. Trong nghiên cứu có 1 trường hợp cuống TM thận ngắn, khi thực hiện miệng nối với tĩnh mạch chậu ngoài $\mathrm{TM}$ chậu của người nhận bị rách, đầu trên của tĩnh mạch chậu ngoài được nối tận tận với TM thận, đầu dưới của TM chậu còn lại được tái tạo Homograft rồi thực hiện miệng nối tận bên với tĩnh mạch chủ dưới. Có 1 trường hợp có 2 tĩnh mạch thận trong đó có $1 \mathrm{TM}$ ngắn phải tạo hình ghép đoạn tĩnh mạch sinh dục. 
Tại Việt Nam, năm 2010 Dư Thị Ngọc Thu và cộng sự [8] thông báo kỹ thuật chuyển vị mạch máu chậu - thận ghép trong ghép thận tại bệnh viện Chợ Rẫy. Nghiên cứu được tổng kết trên 195 trường hợp ghép thận trong thời gian 18 năm. Tác giả khuyến cáo: lựa chọn hố chậu phải để ghép cho tất cả các trường hợp; nếu tĩnh mạch thận ngắn (về mặt giải phẫu học hoặc do kỹ thuật lấy) để tránh tạo hình tĩnh mạch thận bằng tĩnh mạch tự thân hoặc nhân tạo, tác giả kết hợp kỹ thuật bóc tách vùng rốn thận, chuyển vị động mạch, tĩnh mạch thận ghép và chuyển vị động mạch, tĩnh mạch chậu ngoài sau đó nối ĐM thận tận tận với ĐM chậu trong, tĩnh mạch thận tận bên với tĩnh mạch chậu ngoài.

Thời gian thực hiện miệng nối mạch máu: Thời gian thực hiện miệng nối động mạch trung bình của nhóm có biến đổi giải phẫu mạch máu thận cao hơn nhóm không có biến đổi giải phẫu với thời gian lần lượt là $18.68 \pm 8.52$ phút và $13.10 \pm 3.26$ phút. Thời gian thực hiện miệng nối tĩnh mạch của 2 nhóm trên lần lượt là $13.83 \pm 5.89$ phút và $12.87 \pm 4.08$ phút. Theo nghiên cứu của Trần Văn Sáng và cộng sự, thời gian thực hiện miệng nối tĩnh mạch trung bình là 28 phút (nhanh nhất là 15 phút, lâu nhất là 70 phút) [5].

Thời gian thiếu máu thận ghép: Thời gian thiếu máu nóng trung bình của nhóm có biến đổi giải phẫu và không có biến đổi giải phẫu là $1.81 \pm 1.21$ phút và $1.57 \pm 0.99$ phút. Thời gian thiếu máu ấm của 2 nhóm lần lượt là $31.09 \pm 11.05$ phút và $25.92 \pm 5.58$ phút. Thời gian thiếu máu lạnh của 2 nhóm lần lượt là $29.80 \pm$ 12.09 phút và $30.96 \pm 10.68$ phút. Nghiên cứu của Thái Minh Sâm và cộng sự [6] cho thấy, thời gian thiếu máu nóng trung bình là 1 phút 40 giây, ngắn nhất là 45 giây, dài nhất là 4 phút. Thời gian thiếu máu ấm trung bình là 50 phút (ngắn nhất là 35 phút, dài nhất là 85 phút). Thời gian thiếu máu lạnh trung bình là 38 phút (ngắn nhất là 17 phút, dài nhất là 75 phút).

\section{KẾT LUẬN}

Qua nghiên cứu 120 trường hợp ghép thận người cho sống được thực hiện tại bệnh viện Việt Đức, trước mổ có $51 / 120$ trường hợp thận dự kiến lấy có biến đổi giải phẫu mạch máu thận chiếm tỷ lệ $42.5 \%$. Sau khi lấy thận, tỷ lệ biến đổi giải phẫu mạch máu thực là
58/120 (48.33\%). Trong đó biến đổi giải phẫu động mạch gặp 47 trường hợp (39.17\%) và 11 biến đổi giải phẫu tĩnh mạch thận $(9.17 \%)$. Việc nắm vững giải phẫu mạch máu thận trước ghép và sau khi lấy thận đóng vai trò hết sức quan trọng vào thành công của ghép thận.

\section{TÀI LIỆU THAM KHẢO}

1. Đỗ Tất Cường, Bùi Văn Mạnh, Lê Việt Thắng, Phạm Quốc Toản, Hoàng Trân Anh. (2010). Nhận xét về kết quả các trường hợp ghép thận tại bệnh viện 103. Y học Việt Nam. 2, 306-310.

2. Lê Trung Hải và cộng sự. (2004). Một số kinh nghiệm bước đầu qua ghép thận từ người cho sống. Tạp chi ngoại khoa. 54(4):11-14.

3. Kawamoto S, Fishman EK. (2006). MDCT angiography of living laparoscopic renal donors. Abdom imaging, 31, pp 361-373.

4. Đỗ Ngọc Sơn, Nguyễn Tiến Quyết, Vũ Nguyễn Khải Ca và cộng sự. (2014). Kết quả phẫu thuật ghép thận từ người cho sống tại Bệnh viện Việt Đức. Tạp chí y dược học quân sụ. 39,158-162.

5. Trần Văn Sáng, Trần Ngọc Sinh, Chu Văn Nhuận và cộng sự. (2001). Mổ ghép thận thực nghiệm tại bệnh viện Chợ Rẫy. Tạp chi Y hoc Việt Nam. 4,5,6:55-59.

6. Thái Minh Sâm, Từ Thành Trí Dũng, Dương Quang Vũ và cộng sự. (2001). Nhân 16 trường hợp rửa và bảo quản thận trong ghép thận tại bệnh viện Chợ Rẫy. Y hoc Việt Nam. 4,5,6:67-69.

7. Satyapal KS, Kalideen JM, Haffejee AA, Singh B, Robbs JV. (1999). Left renal vein variations. Surg Radiol Anat.

8. Dư Thị Ngọc Thu, Chu Văn Nhuận, Dương Quang Vũ và cộng sự. (2010). Kỹ thuật chuyển vị mạch máu chậu - thận ghép trong ghép thận tại bệnh viện Chợ Rẫy. Y hoc Việt Nam. 2, 512-515

9. Bewick M, OGG CS, Parsons V et al. (1990). The arterial complications of 500 renal transplants. British Journal of Urology. 40, 186-190.

10.Coen LD, Raftery AT. (1992). Anatomical variations of the renal arteries and renal transplantation. Clincal Anatomy. 5, 425-432. 